\title{
Human Seminal Plasma Fibrinolytic Activity
}

Patrick Van Dreden, Ph.D., ${ }^{1}$ Audrey Carlo, M.D., ${ }^{1}$ and Aurélie Rousseau, M.Sc. ${ }^{1}$

The publisher regrets an error in the names of the second and third authors of the abovementioned article in Seminars in Thrombosis and Hemostasis, Volume 33, Number 1, page 21. The names in the article were written last name first (Carlo Audrey, M.D., and Rousseau Aurélie, M.Sc), and are correctly written in the authorship line above (Audrey Carlo, M.D., and Aurélie Rousseau, M.Sc.).

${ }^{1}$ Stago Research and Development, Gennevilliers, France. Address for correspondence and reprint requests: Patrick Van Dreden, Ph.D., Stago R\&D, Recherche Prospective, PAE Parispace 3, 125 avenue Louis Roche, 92635 Gennevilliers Cedex, France (e-mail: pvandreden@stago.fr).

Thrombophilia in Clinical Practice; Guest Editors, Saskia
Middeldorp, M.D., Ph.D., and Marcel Levi, M.D., Ph.D.

Semin Thromb Hemost 2007;33:617-618. Copyright (C) 2007 by Thieme Medical Publishers, Inc., 333 Seventh Avenue, New York, NY 10001, USA. Tel: +1(212) 584-4662. DOI 10.1055/s-2007-986458. ISSN 0094-6176. 